Letter to the Editor

\section{Weathering phases recorded by gnammas: Response to comments by Norwick, Pages 400-401}

The discussion by Dr. Norwick introduces a gnamma morphometry model with two scenarios. This approach is of great interest and we believe it could improve the understanding of gnammas. However, we consider that the model constraints are inappropriate and do not agree with gnamma morphometry observations, and they do not take into account the diverse processes involved in the different evolution stages of gnammas.

The model presented is based in the assumption that erosion at the base of the gnamma and in the spillway have different rates. This causes a negative (scenario 1 ) or positive (scenario 2 ) correlation between the maximum depth of the gnamma $(h)$ and the minimum height of the cavity $(u)$ that occurs at the spillway. Thus, according with scenario 1 the spillway is eroded more rapidly than the base of the cavity. This scenario is thought to follow the descriptions of gnamma evolution by Domínguez-Villar (2006), Domínguez-Villar and Jennings (2008) and Domínguez-Villar et al. (2009). However, this scenario is contrary to what is observed and reported in these publications; the constraints of scenario 1 are based on a misunderstanding and do not represent the data described.

Here it is worth noting the use of the term "armchair gnamma" in the discussion by Dr. Norwick. As originally described by Twidale and Corbin (1963) and in later reviews (e.g., Twidale, 1982), an armchair gnamma is considered a gnamma developed on a certain slope (e.g., $>20^{\circ}$ ), and is independent of its capacity to retain water. We recommend the strict use of this term to avoid confusion.

Nowrick's scenario 2 is thought to be a better approximation to describe gnammas and considers that gnammas deepen faster than their spillway is eroded (i.e., " $h$ " is eroded slightly faster than " $u$ "). This assumption is exclusively based on the positive correlation between " $h$ " and " $u$ " parameters. However, the basic constraint of scenario 2 is not supported by real data. The field observations from Serra da Estrela indicate that while $\delta$-value increases (i.e., gnammas are older), the " $u$ " remains relatively constant and there is no significant increase or decrease on its magnitude (Fig. 1a). This is common to all gnammas we have studied, not just to the set here presented (see Domínguez Villar, 2007). According to scenario 2, the depth ratio is reported to stabilize with increasing " $h$. ." Again we suggest being strict with the terminology and not confuse depth ratio (an individual gnamma parameter) with $\delta$-value (a filtered gnamma subpopulation parameter).

We have plotted depth ratio of Serra da Estrela gnammas against their " $h$ " (Fig. 1b) and the results differ from those of the model. Field data show a positive correlation with a large heteroscedasticity and no signs of depth-ratio stabilization. These results are common to all the measurement stations we have studied in different sites along the world (Domínguez Villar, 2007). Additionally, the positive correlation between " $h$ " and " $u$ " shown by scenario 2 fails to reproduce subpopulations. Replication of $\delta$-value signatures in two measurement stations in Serra da Estrela and six measurement stations in the
Spanish Sierra de Guadarrama (Domínguez Villar, 2007) confirm that they cannot be the result of a random process. In fact, the calculation of sub-populations follows a rigorous statistical process (Domínguez-Villar and Jennings, 2008) and statistical significance is always reported (Domínguez Villar, 2007; Domínguez-Villar and Jennings, 2008; Domínguez-Villar et al., 2009).

In summary, the basic assumption used to run the model, "different erosion rates at the base and in the spillway of gnammas," is not supported by field data. This provides modelled gnammas with a morphology that does not resemble real gnammas. Therefore, the proposed model is not validated by field data and does not represent real gnammas in nature.

Dr. Norwick suggested that the gnammas in a certain region are formed shortly after the rock exposure and that no further gnammas are thereafter formed. This hypothesis is supported by results of the modelling according to scenario 2 , which provide stable depth ratios

a

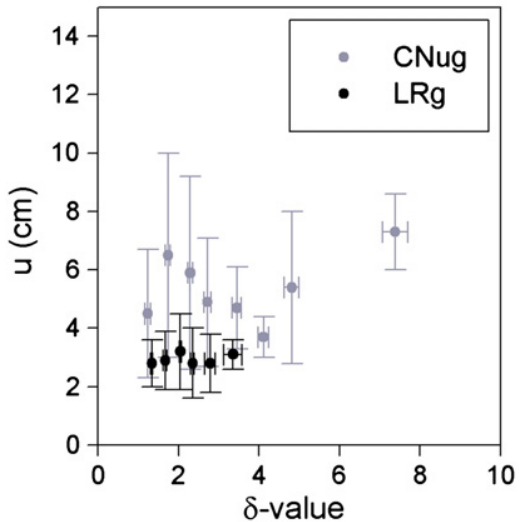

b

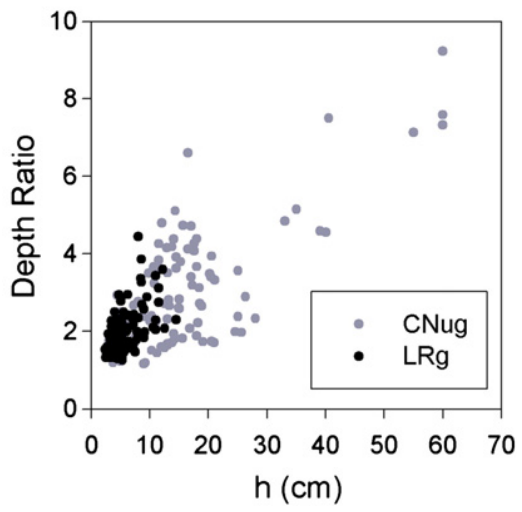

Figure 1. Morphometric properties of gnammas from two measurements stations in Serra da Estrela. a) Average spillway height $(u)$ against $\delta$-value (relative time chronometer). b) Depth ratio against maximum depth $(h)$ of gnammas. 


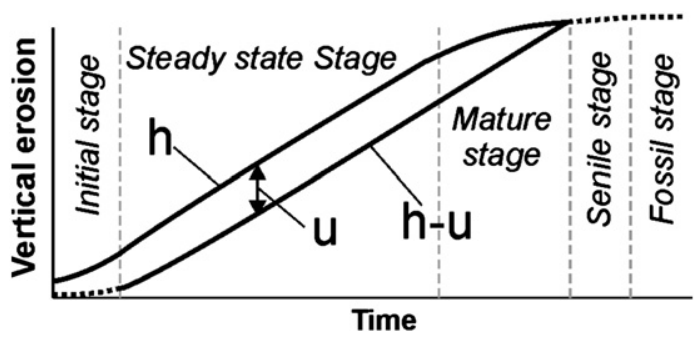

Figure 2. Simplified scheme showing the evolutionary stages in gnammas, where the parameter " $h-u$ " represents the erosion over the spillway. The spillway height $(u)$ is the difference between " $h$ " and " $h-u$." The duration of each stage is not to scale.

after an initial stage, and by the lack of observation of large and small gnammas in the same areas. We have demonstrated here that the model proposed does not represent real gnammas in nature and it should not be used to support such conclusions. Additionally, our results show that the volume of gnammas from measurement stations with several sub-populations varies by 2 or 3 orders of magnitude $(<1$ to $>1000$ litres). These data have been reported in all of our morphometry analyses (Domínguez-Villar, 2006, 2007; Domínguez-Villar and Jennings, 2008; Domínguez-Villar et al., 2009). Therefore, based in our experience, we consider more realistic for gnammas to develop continuously or episodically (depending on the environmental conditions affecting weathering) from the time of rock exposure.

The model presented by Dr. Norwick studies the evolution of gnammas and is exclusively based in morphometry, but it does not consider weathering processes. During the evolution of a gnamma the importance of a series of weathering processes differs and has a significant impact in its morphometry. We consider here five evolutionary stages: initial, steady sate, mature, senile, and fossil (Fig. 2). During the initial stage a gnamma cavity is formed. At this stage no substantial water accumulation in a sub-aerial environment takes place. The steady-state stage represents an environment in which a certain water level stays in the cavity at least some time (days/ months) per year, and the weathering is both sub-aerial and subaqueous. All the gnammas we used in all our previous studies (what we called "active gnammas") are restricted to this evolutionary stage in order to compare morphologies affected by relatively similar weathering processes. In the mature stage the erosion at the base of the gnamma is reduced in relation to the spillway and the capacity to retain water is limited, affecting the weathering processes and the gnamma morphometry. Excessive sediment supply to the cavity preventing the erosion at the base of the gnamma can be a cause to pass from a steady-state to a mature stage. The senile stage occurs when the cavity does not accumulate water inside the cavity and erosion does not differ much from the rest of the rock. In a fossil stage the gnamma morphology is partly or mostly lost due to rock weathering.

The duration of each stage varies for different gnammas since local conditions are critical. The dominating weathering processes and the rate of rock erosion greatly differ between stages. Therefore, we consider that gnamma models should focus in a particular stage or include different scenarios to each stage, according to the weathering processes and their weathering rates.

\section{References}

Domínguez-Villar, D., 2006. Early formation of gnammas (weathering pits) in a recently glaciated area of Torres del Paine, southern Patagonia (Chile). Geomorphology 76, 137-147.

Domínguez Villar, D., 2007. Análisis morfométrico de pilancones: consideraciones genéticas, evolutivas y paleambientales. Universidad Complutense de Madrid, Madrid.

Domínguez-Villar, D., Jennings, C.E., 2008. Multi-phase evolution of gnammas (weathering pits) in a holocene deglacial granite landscape, Minnesota (USA). Earth Surface Processes and Landforms 33 (2), 165-177.

Domínguez-Villar, D., Razola, L., Carrasco, R.M., Jennings, C.E., Pedraza, J., 2009. Weathering phases recorded by gnammas developed since last glaciation at Serra da Estrela, Portugal. Quaternary Research 72, 218-228.

Twidale, C.R., 1982. Granite Landforms. Elsevier, Amsterdam.

Twidale, C.R., Corbin, E.M., 1963. Gnammas. Revue de Géomorphologie Dynamique 14, $1-20$.

David Domínguez-Villar Centro Nacional de Investigación sobre la Evolución Humana (CENIEH), Paseo Sierra de Atapuerca s/n, 09002 Burgos, Spain Corresponding author. E-mail address: david.dominguez@cenieh.es.

Javier Pedraza

Departamento de Geodinámica, Universidad de Ciencias Geológicas, C/ José Antonio Novais 12, 28040 Madrid, Spain

Rosa M. Carrasco Departamento de Ingeniería Geológica y Minera, Universidad de Castilla-La Mancha, Av. Carlos III s/n, 45071, Toledo, Spain

5 June 2012 